Check for updates

The BMJ

Cite this as: BMJ 2021;374:n1728 http://dx.doi.org/10.1136/bmi.n1728 Published: 07 July 2021

\section{Covid-19: Adults in poorest areas are almost four times more likely to die, inquiry finds}

\author{
Elisabeth Mahase
}

Working age adults in England's poorest areas were almost four times more likely to die from covid-19 than those in the wealthiest areas, a landmark report has found. ${ }^{1}$

The report, which followed a nine month investigation by the Health Foundation, showed that pre-existing differences in health were associated with worse outcomes. People aged 50 to 69 in the most deprived areas were twice as likely as those in the least deprived areas to have at least two long term health conditions.

In 2020 the UK had the fourth highest excess deaths among the OECD (Organisation for Economic Co-operation and Development) countries and the second highest excess deaths in Europe among people aged under 65.

The Health Foundation has now called on the government to learn from mistakes made after the 2008 financial crisis and to invest in health. The charity's director of health, Jo Bibby, said, "The shortcomings of the response to the 2008 financial crisis left a legacy of deep rooted issues-poor health, increased financial insecurity, and strained public services-which left the UK more vulnerable to the pandemic's health and economic impacts.

"We cannot afford to make the same mistake twice. Government must address the root causes of poor health and invest in jobs, housing, education, and communities. This is the only way to create a healthier society that can meet the challenge ahead and better withstand future crises."

The report said that the timing of pandemic restrictions, population density, and high levels of regional and international travel had worsened outcomes in the UK but that poor underlying health was also a key factor. Countries that showed the greatest improvement in healthy life expectancy over the decade before covid-19 experienced lower excess mortality during the pandemic, while countries with the highest levels of disability adjusted life years lost to diabetes, cardiovascular disease, cancer, or chronic respiratory disease had higher mortality rates.

The inquiry found that people working in elementary, caring, leisure, and other service occupations had higher mortality rates, especially men. This reflected the fact that these sectors remained open but also the low rates and coverage of statutory sick pay and difficulty in accessing isolation payments. This reduced people's ability to self-isolate-increasing exposure and spread and worsening their outcomes.

\section{Future repercussions}

Looking to future repercussions, the report warned that the full impact of the pandemic on household finances was yet to come, with a "crippling blow" expected to hit people in the poorest areas in the form of debt build-up and the discontinuation of the Coronavirus Job Retention Scheme and Universal Credit uplift later this year.

Additionally, "long covid" is set to limit people's ability to do what they were doing before the pandemic. Around one million people-one in five people who tested positive for covid-19-had self-reported being affected by long covid as of May 2021, and women and people from more deprived backgrounds seem to be at particular risk.

The effect of the pandemic and the subsequent restrictions on people's mental health were also noted as concerns, as was the decline in access to social care services despite the rising need. Other issues highlighted by the inquiry included the increase in domestic abuse reports during the first wave of the pandemic, the reduction in child safeguarding referrals while schools were closed or were open only for online learning, and growing differences in access to and uptake of covid-19 vaccination. Figures show that the least deprived areas and white people reported higher coverage than the most deprived areas and people of black Caribbean and Pakistani backgrounds.

“The nation's health has frayed over the past decade and this has contributed to the UK experiencing some of the poorest global outcomes from the covid-19 pandemic," the report said. "Ensuring a recovery that improves health-as well as the economy-will require a cross-government health inequalities strategy with clear targets for improvement and a regular, independent assessment of the nation's health laid before parliament."

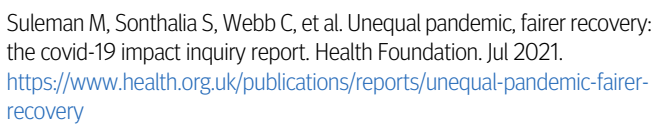

Suleman M, Sonthalia S, Webb C, et al. Unequal pandemic, fairer recovery: the covid-19 impact inquiry report. Health Foundation. Jul 2021. https://www.health.org.uk/publications/reports/unequal-pandemic-fairerrecovery

This article is made freely available for use in accordance with BMJ's website terms and conditions for the duration of the covid-19 pandemic or until otherwise determined by BMJ. You may use, download and print the article for any lawful, non-commercial purpose (including text and data mining) provided that all copyright notices and trade marks are retained. 